\title{
28 Research Square \\ Costing Electronic Private Sector Malaria Surveillance in the Greater Mekong Subregion
}

Ann Levin ( $\square$ ann@levinmorgan.com )

Levin \& Morgan LLC https://orcid.org/0000-0002-7417-7648

\section{Rebecca Potter}

University of Oslo

Kemi Tesfazghi

Population Services International

\section{Saysana Phanalangsy}

Population Services International

\section{Phally Keo}

Population Services International

\section{Elijah Filip}

Clinton Health Access Initiative

\section{Si Hein Phone}

Network of Aquaculture Centres in Asia-Pacific

\section{James Eliades}

Independent Consultant

\section{Research}

Keywords: Malaria, surveillance, Cost, private sector

Posted Date: November 4th, 2020

DOI: https://doi.org/10.21203/rs.3.rs-100621/v1

License: (c) (1) This work is licensed under a Creative Commons Attribution 4.0 International License.

Read Full License

Version of Record: A version of this preprint was published at Malaria Journal on April 20th, 2021. See the published version at https://doi.org/10.1186/s12936-021-03727-w. 


\section{Abstract}

Background: Private sector malaria programs contribute to government-led malaria elimination strategies in Cambodia, Lao PDR, and Myanmar by increasing access to quality malaria services and surveillance data. However, reporting from private sector providers remains suboptimal in many settings. To support surveillance strengthening for elimination, a key program strategy is to introduce electronic surveillance tools and systems to integrate private sector data with national systems, and enhance the use of data for decision-making. During 2013-2017, an electronic surveillance system based on open source software, District Health Information System 2 (DHIS2), was implemented as part of a private sector malaria case management and surveillance program. The electronic surveillance system covered 16,000 private providers in Myanmar (electronic reporting conducted by 200 field officers with tablets), 710 in Cambodia (585 providers reporting through mobile app), and 432 in Laos (250 providers reporting through mobile app).

Methods: We conducted a study to document the costs of introducing electronic surveillance systems and mobile reporting solutions in Cambodia, Lao PDR, and Myanmar, comparing the cost in different operational settings, the cost of introduction and maintenance over time, and assessing the affordability and financial sustainability of electronic surveillance. The data collection methods included extracting data from PSI's financial and operational records, collecting data on prices and quantities of resources used, and interviewing key informants in each setting. The costing study used an ingredients-based approach and estimated both financial and economic costs.

Results: Annual economic costs of electronic surveillance systems were $\$ 130,293$ in Laos, $\$ 221,749$ in Cambodia, and \$504,456 in Myanmar. The annual economic cost per private provider surveilled was \$32 in Myanmar, \$379 in Cambodia, and \$521 in Laos. Cost drivers varied depending on operational settings and number of private sector outlets covered in each country; whether purchased or personal mobile devices were used; and whether electronic (mobile) reporting was introduced at provider level or among field officers who support multiple providers for case reporting.

Conclusion: The study found that electronic surveillance comprises less than $1 \%$ of National Malaria Strategic Plan cost and $6 \%-8 \%$ of surveillance budgets and deemed to be affordable and financially sustainable.

\section{Background}

The World Health Organization (WHO) urges national malaria programs to transform surveillance into a core intervention to drive progress from control to elimination [1]. Countries in the Greater Mekong Subregion (GMS) are updating national systems to support the requirements of surveillance in elimination settings. National malaria control programs (NMCPs) are considering whether and how to transition from aggregate, paper-based reporting systems to real-time, case-based electronic systems. The rapid growth of smart phone ownership and mobile coverage in the GMS [2] is also prompting 
NMCPs and malaria partners to integrate mobile reporting solutions into surveillance systems to increase the timeliness and granularity of case reporting.

Population Services International's Greater Mekong Subregion Elimination of Malaria through Surveillance (GEMS) program, funded by the Bill and Melinda Gates Foundation (BMGF), contributed to government-led malaria elimination strategies in Cambodia, Lao PDR, and Myanmar and Vietnam by developing electronic systems for private sector providers during the 2013-2017 period. In response to increasing demand for real-time case-based reporting and analysis, the GEMS program designed and configured an electronic surveillance platform in DHIS2, developed open-source mobile applications for real-time reporting, and scaled mobile reporting tools across private sector networks. Malaria case data reported by PSI's networks of private providers and captured through the GEMS surveillance platform were integrated into national systems at varying degrees of frequency and granularity, in accordance with NMCP reporting protocols and depending on the readiness of national surveillance systems. As a result of the intervention, the timeliness of private provider reporting a suspected or positive malaria case was reduced from a month to less than 24 hours in Cambodia and Lao PDR. In Myanmar, the 16,000 private providers went from not reporting their malaria cases to reporting these monthly.

The study authors conducted cost analyses in parallel with program implementation to provide information on the key cost drivers and assess affordability and financial sustainability of introducing and maintaining electronic surveillance approaches across three operational settings in Cambodia, Lao PDR, and Myanmar, as well as to estimate the comparative costs of approaches in different programmatic settings.

Cambodia, Lao PDR, and Myanmar have committed to achieving malaria elimination by 2030, although each country is at a different stage in the elimination pathway in terms of each country's epidemiology and the readiness of surveillance and response systems. $[3,4,5]$ Malaria caseloads and mortality rates continue to fall, and malaria transmission is becoming increasingly localized. Transmission hot spots are often concentrated in and around forested areas, affecting populations who live or work in these areas. As a result, many of the "last mile" malaria cases are expected to occur in remote areas, where access to public health services can be poor. Large proportions of malaria patients in the GMS seek and receive malaria treatment from the private sector. Proportions vary depending on key demographic indicators, such as living in urban or rural locations and wealth quintile, with estimates of up to $65 \%$ of the population seeks malaria care in the private sector in Myanmar and 75\% in Cambodia [6]. In Lao PDR, a study in a malaria endemic districts showed that $77 \%$ of patients first sought care in the private sector.[7\} Private sector malaria providers include formal health care providers such as clinics and pharmacies, as well as non-formal outlets, including drug shops, mobile drug vendors, and general retailers according to varying national policies.

The PSI GEMS project has been working with large networks of private sector outlets and providers both formal and non-formal located in areas of transmission - to facilitate case reporting into national surveillance systems and ensure that NMCPs have access to complete data for evidence-based decision 
making. The project used DHIS2, an open-source health management information system adopted by more than 60 countries worldwide, as an electronic platform to collect, analyze, and report routine surveillance data from the private sector. Ministries of Health in Myanmar and Lao PDR also use DHIS2 as a national health management information system. The project designed, developed and scaled mobile reporting applications to improve timeliness of case-based reporting from private providers. These tools include PSI's custom-developed Malaria Case Surveillance app and the University of Oslo's generic, freely available DHIS2 mobile app. Both tools enable providers to submit case data to DHIS2 in near realtime through Android mobile devices.

Despite substantial investments in surveillance system strengthening, the evidence on affordability and feasibility of financially sustaining private sector surveillance in elimination settings is limited. Most studies on surveillance costs focus on other enhancements such as improved diagnostic methods [8] or GIS systems [9]. The purpose of this study is to provide estimates on the affordability and financial sustainability of electronic surveillance interventions through an analysis and comparison of the costs in Cambodia, Lao PDR, and Myanmar. These insights will provide evidence to NMCPs and partners to inform national decisions on resource allocation and surveillance strengthening strategies.

\section{Methods}

\section{Study Area}

The costing study was conducted in three countries: Cambodia (fourteen out of twenty-five provinces), Lao PDR (five out of seventeen provinces), and Myanmar (nationwide) from 2017-2018. The electronic surveillance system covered 16,000 private malaria providers in Myanmar using 200 field officers to collect data with PSI-provided tablets; it covered 710 private providers in Cambodia, including 585 providers reporting through PSI-provided smartphones devices using PSI's Malaria Case Surveillance App and 125 provided using paper-based reporting; and it covered 432 providers in Lao PDR, with 250 private providers reporting through personal smartphone devices using PSI's Malaria Case Surveillance App) and 182 using paper-based reporting.

In Myanmar, malaria providers included formal private providers (general practitioners), non-formal private providers (e.g. general retailers, drug shops) and community-based health providers. In Laos, malaria providers included formal private providers (clinics and pharmacies). In Cambodia, malaria providers included formal private providers (clinics, health cabinets) and providers based on private worksites in high risk areas (e.g. plantations).

\section{Study Design}

A micro-costing approach (ingredients-based) [5] was applied to estimate the value of resources used in the surveillance interventions. The resources (costing inputs) used for every activity were identified and a unit cost attached to each resource. The list of activities was agreed upon through discussions with implementing and finance program staff in the study countries and are shown in Table 1. Activities are 
not limited to the software itself; the list includes all activities that are required for reporting case data from private providers into the electronic system and generating automated analytics outputs.

The costs of the private provider surveillance system has two components: 1) the electronic surveillance system that includes the design, configuration and maintenance of the DHIS 2 platform for malaria surveillance; and 2) mobile reporting that refers to the application design, application development, piloting applications, and training providers as well as data packages, upgrades and maintenance, refresher training and supervision.

The study perspective is the payer's (PSI's GEMS project) and financial and economic costs were differentiated. Financial costs are monetary outlays spent by implementers on resources used for electronic surveillance interventions whereas economic costs include all costs, including opportunity costs (e.g. the value of private providers' time spent in program activities such as training and supervision as well such as donated goods and volunteer time).

Activity costs were categorized as "start-up", "capital" or "recurrent". Start-up costs are one-time activities to prepare for the project such as initial training, system design, and mobile application design. In the case where capital costs (e.g. smartphones, tablets, desktops, computer servers) were used, these were amortized as part of the total cost estimates. Recurrent costs include the value of resources that last less than one year. For financial costs, straight-line depreciation was used (i.e. the capital costs were divided by the number of useful life years) while amortization and discounting was used in economic costs. Research costs were excluded from the estimation.

The study team estimated total costs and cost per provider for the cost of the electronic surveillance system and cost of mobile reporting.

\section{Study timing and duration}

Data collection took place between October 2017 and May 2018. Costs associated with the introduction and maintenance of surveillance interventions were included in the study based on the timing of implementing these interventions in each participating country. The study assumed an implementation period of three years to enable comparison across countries. The study team collected cost data for the period from October 2013 through September 2017 in Cambodia; from April 2016 through September 2017 in Lao PDR, and from November 2015 through September 2017 in Myanmar. Costs were derived by assigning values to resources utilized such as training and private provider time spent in training and monthly meetings, and quantities utilized. The data collection was informed in part by discussions with key informants from key stakeholders in each setting.

\section{Affordability and Financial Sustainability}

To assess financial sustainability, the study team assessed the government's ability to fund malaria surveillance by comparing the annual cost of electronic surveillance with the annual costs of implementing its national malaria strategic plans and surveillance. 


\section{Results}

\section{Cambodia}

In Cambodia, the project developed a custom mobile reporting app, the Malaria Case Surveillance App (MCS), for providers to be able to report cases directly to DHIS2 through a mobile smartphone device. The project procured and equipped 585 of 710 private providers with smartphones, trained providers to report cases through the mobile app, and provided monthly data packages to the private providers to support use of the app.

Table 2 shows the financial and economic costs for introducing electronic surveillance and mobile reporting in Cambodia during three years by cost category: start-up, capital or recurrent. Total financial costs for the Cambodian intervention were $\$ 434,968$, while annual financial costs were $\$ 144,989$. Total economic costs were $\$ 891,748$ in total and 297,249 annually. Economic costs included the value of DHIS2 software, a global public good supported by the University of Oslo that makes the software freely available[1] as well as private provider time spent on training and electronic and paper reporting. As can be seen, the costs to the payer (financial costs) are higher for mobile reporting than for introduction of electronic surveillance with DHIS2. This is due to the cost of the mobile phones and the monthly data packages. However, both costs are similar for economic costs when the value of the 'free' DHIS2 software are taken into account.

The largest share of financial total costs (47\%) went for recurrent costs, followed by start-up activities and capital goods ( $26 \%$ and $27 \%$, respectively), due to the cost of the monthly mobile data packages and other costs of implementation. The largest share for economic costs, was for start-up (43\%) (see Figure $1 b)$, due to the inclusion of the value of DHIS2 software.

\section{Lao Electronic Surveillance}

Table 3 shows that total financial costs for the Lao intervention were $\$ 152,878$, while annual costs were $\$ 50,959$. Total economic costs were $\$ 390,880$ while annual costs were $\$ 130,293$. Economic costs also accounted for the value of the DHIS2 software and the estimated cost of providers' personal mobile devices as in Cambodia. For financial costs, the largest share of total costs was for recurrent costs (54\%) due to the high cost of supervision (29\%). Among economic costs, start-up costs had the highest share (58\%) due to the inclusion of the value of DHIS2 software (43.1\%). Similar to Cambodia, the financial cost of mobile reporting is higher than that of electronic surveillance.

\section{Myanmar Electronic Surveillance}

Table 4 shows the financial and economic costs of introducing electronic surveillance and mobile reporting in Myanmar. The mobile reporting model employed in Myanmar is different from Cambodia and Lao PDR. In Myanmar, 200 field officers employed by PSI Myanmar reported electronically to DHIS2 with tablets when they visit providers monthly rather than providers using smartphones to report directly. Providers maintained paper records for primary reporting. Further, PSI Myanmar did not design or develop 
a customized mobile application for reporting. Instead, PSI Myanmar used a free generic, open-source DHIS2 reporting app made.

Total financial costs for the Myanmar intervention were $\$ 1,316,379$, while annual financial costs were $\$ 437,954$. Total economic costs were $\$ 1,569,253$ and $\$ 503,901$ annualized. Economic costs also accounted for the value of DHIS2 software as in the other two countries. The economic cost of the custom app was $\$ 25,979$, with no financial costs incurred by the program for development. The annual financial and economic costs per provider were $\$ 27$ and $\$ 32$, respectively.

Recurrent costs represented $88 \%$ of the total share of financial costs. The cost driver was monthly supportive supervision to providers for capturing surveillance data from paper records. For economic costs, recurrent costs also had the largest share of total costs (77\%) due to the high cost of supervision.

\section{Comparison of Electronic Surveillance Costs in Cambodia, Laos, and Myanmar}

Cost structure varied across the three countries depending on the cost drivers, the size of the networks and the manner in which electronic reporting was implemented i.e. individual provider level in Cambodia and Lao PDR and supervisor level in Myanmar. Myanmar's coverage was national with a large number or providers covered $(16,000)$ that resulted in a high annual economic cost $(\$ 504,456)$, primarily due to the cost of supervision, but a low annual cost-per-provider covered (\$32) (Table 4). The numbers of providers covered in Lao PDR was much smaller $(n=432)$, leading to a lower annual economic cost $(\$ 130,293)$, but a higher cost-per-provider (\$521) (Table 3). Cambodia had a network size (710) closer to Lao PDR's and thus a similar annual economic cost-per-provider covered (\$379). However, because the project in Cambodia developed the mobile app and purchased smartphones and data packages for all the providers, the annual economic costs were higher $(\$ 221,749)$ (Table 5).

Neither Myanmar or Lao PDR developed a mobile app or purchased smartphones for their providers. Thus, supervision was the primary cost driver for financial cost.

Economic costs were compared to the annual national malaria strategic plans' (NMSP) budgets in all three countries, and to the proportion specifically budgeted for surveillance in Lao PDR and Myanmar (there was no surveillance budget in the Cambodian NMSP). The total annual cost of PSI's electronic surveillance intervention in the three countries comprised $0.4-0.9 \%$ of the total annual NMSP budget, and 5.8-7.9\% of the total NMSP surveillance budget in Lao PDR and Myanmar (Table 5).

\section{Footnote:}

[1] It was estimated that supporting a new software for the system would cost $\$ 150,000$ in in total or $\$ 50,000$ per year; and routine maintenance upgrades to the software were valued at $\$ 30,000$ total and $\$ 10,000$ per year.

\section{Discussion}


Surveillance systems are a core intervention in malaria elimination settings (6). Case-level data is needed from all health points of care that are diagnosing and treating malaria in order to properly estimate and allocate resources, target interventions, and implement elimination protocols. In many malaria endemic countries, private sector providers perform a significant proportion of case management and should be included in surveillance activities. Yet there is little evidence for national programs to accurately cost the inclusion of private sector providers in malaria surveillance systems in elimination settings. The costing of electronic surveillance systems to capture private sector malaria case data in Cambodia, Lao PDR, and Myanmar can provide a template for national programs on elements to consider when costing out such a system, the main cost drivers, and how to implement in the most cost-effective way in different operational settings to promote affordability and financial sustainability.

Total annual costs of introducing electronic surveillance and mobile reporting were \$130,293 in Lao PDR, $\$ 221,749$ in Cambodia, and $\$ 504,456$ in Myanmar. The cost drivers differed by country but were recurrent costs for financial costs in all three countries and startup for economic costs for Cambodia and Lao PDR since donated software and hardware were included. For Myanmar which had fewer hardware costs, the economic cost driver was supervision, a recurrent cost.

In Cambodia and Lao PDR, providers could report directly into the electronic surveillance system and there was less need for monthly data collection. Thus, supervision only accounted for $8 \%$ and $11 \%$ of the total annual economic costs in Cambodia and Lao PDR, respectively. While the network had a similar size in Lao PDR (432 in Lao PDR and 710 in Cambodia), the providers used their own smartphones and, as a result, a higher proportion of the total annual economic costs went towards supervision (47\%).

Myanmar had a lower cost per provider reporting malaria case data since it employed field officers to visit clinics monthly and record the data in tablets. This approach could be particularly useful in sub-national areas that have already developed a supportive supervision model and where it is geographically feasible to visit providers at least monthly. While this increases the proportion of total annual economic cost spent on supervision (70\% in Myanmar), its costs were much lower due to the reduced need for mobile phones and monthly mobile data packages. However, such a system impacts timeliness, with reporting only occurring periodically rather than in real-time. Alternative solutions can be considered as caseloads drop. As sub-national areas approach elimination, field officers could be replaced or complemented with a system that targets smartphone purchase for higher case-load providers. For providers with few cases, a simple phone call to field officers could be utilized to complete required reporting and initiate malaria elimination surveillance protocols. While the PSI GEMS project was an NGO-supported, malaria-focused surveillance program, NMPs may identify other efficiencies, such as incorporating supervision and data collection for private sector providers into existing public sector implementation programs and including private sector providers when training public sector providers.

Some lessons learned about cost-efficiencies can be found from comparing the three settings. In Cambodia, smartphones were purchased for all providers and this made up $26 \%$ of the total annual economic cost of the intervention with an additional $23 \%$ spent on mobile-date packages. In Lao PDR 
where providers used their own smartphones or those that were donated (37\% of providers in Lao PDR had their own phone, the other $63 \%$ received donated phones), the cost was half that proportion, and in Myanmar, where 200 tablets were purchased for supervisors to then collect and send the data from the 16,000 providers, the costs were just above $5 \%$ of the total. Implementing mobile-based reporting where smartphone ownership is high may limit the costs of purchasing new phones and could be considered where provider networks are large. In settings where personal ownership of smartphones is low and Internet connectivity is variable, a model such as Myanmar's could be used.

There are lessons in the three study countries that NMPs can consider when balancing the need to purchase smartphones and mobile-data packages, and the costs of supervision and data collection based on the size of the network. Rather than waiting until national caseloads are approaching elimination levels, high-burden countries could begin to explore options early on in preparation for an elimination-ready surveillance system. This system will need to capture case data from all types of providers, perhaps by focusing on areas of relatively lower transmission or other practical considerations that can eventually inform national elimination strategy. In the future, as internet connectivity is improved, governments can also consider having providers use already existing social media apps to send data on malaria cases.

All three countries are lower-middle income countries and should start absorbing programmatic costs. Recurrent financial costs, costs that governments will need to assume over time, were larger than capital and start-up costs in all three countries (47-88\%). NMPs will need to ensure that recurrent costs are budgeted for over time. These may include costs associated with maintenance, upgrades, hosting, mobile data packages, and regular visits for data quality checks, supervision, and for providers without the ability to report themselves through mobile apps, to collect and report data.

Electronic surveillance appears to be affordable in the three study countries if one assumes that the cost estimated for implementing the national malaria strategic plans are accurate. The cost of introducing electronic surveillance is only a small percentage $(0.4-0.9 \%)$ of the total malaria program budgets, so that even when considering the addition of costs associated with implementation of public sector surveillance, inclusion of private sector providers is very likely feasible. Illustrative of that point in Lao PDR and Myanmar are the percentage of the electronic surveillance costs calculated in this study to the estimated surveillance budget in the NMSP (Cambodia's NMSP did not have a specific budget line for surveillance), $5 \%$ and $25 \%$ respectively. Myanmar demonstrates the potential for countries with very large, nationally active, private sectors to implement an affordable electronic surveillance system.

The development of health information architecture is also an important factor in developing surveillance systems. The lack of adequate health information architecture to capture high quality case-based data has been cited as a gap in the performance of surveillance systems (Lourenco $2019 \mathrm{MJ}$ citation). In the three study countries, the proportion of total economic costs to start-up an electronic DHIS2 ranged between $17-58 \%$ of total costs and included system design, configuration, server set-up, and piloting and training of personnel on DHIS2. Again, recurrent annual costs are important to consider, and in the three 
study countries ranged between $39-77 \%$ of the total annual economic costs. Budgeting to develop these systems now while in a control-phase with an eye to real-time, case-based reporting could potentially facilitate the transition to surveillance as a core intervention that goes hand-in-hand with case management.

The study had some limitations. We were unable to assess the benefits of the electronic surveillance. In addition, other factors that may affect the cost of supervision, such as difficulty of travel and proximity of supervisors to the providers they were overseeing, were not taken into account for this analysis.

\section{Conclusion}

Costing the PSI electronic surveillance system in three study countries in the Greater Mekong Sub-region with unique operational elements can be used to inform other countries' decision-making on planning for an electronic surveillance system that captures private sector data into national surveillance systems as per WHO recommendations. Recurrent annual cost estimates are particularly useful considering the long tail of elimination and the need to maintain surveillance activities until elimination is achieved and to prevent re-introduction.

\section{List Of Abbreviations}

BMGF Bill and Melinda Gates Foundation

DHIS2 District Health Information System 2

GEMS Greater Mekong Subregion Elimination of Malaria through Surveillance

GMS Greater Mekong Subregion

Lao PDR Lao People's Democratic Republic

NMCP National malaria Control Programs

PSI Population Services International

SBCC Social and behavior change communication

WHO World Health Organization (WHO)

\section{Declarations}

\section{Ethics approval and consent to participate}

Not applicable 


\section{Consent for publication}

Not applicable

\section{Availability of data and materials}

The datasets used and/or analyzed during the current study are available from the corresponding author on reasonable request.

\section{Competing interests}

The authors declare that they have no competing interests.

\section{Funding}

The authors were supported by the Bill and Melinda Gates Foundation.

\section{Authors' contributions}

$\mathrm{AL}, \mathrm{RP}$, and JE contributed to the conception and design of the study. KT, SP, PK, EF, and SHP were involved in cost data collection. AL and RP worked on analysis of the data. All co-authors have been involved in drafting the manuscript or revising it critically for important intellectual content. All co-authors have given final approval of the version to be published.

\section{Acknowledgements}

We would like to thank the BMGF for funding the study.

\section{References}

1. World Health Organization, Global Technical Strategy for Malaria: 2016-2030. Geneva, Switzerland, 2015.

2. The Mobile Economy, GSMA Intelligence, 2020.

3. Kingdom of Cambodia Ministry of Health, Cambodia Malaria Elimination Action Framework 20162020. 2016.

4. Lao PDR Ministry of Health, National Strategic Plan for Malaria Control and Elimination 2016-2020, 2016.

5. Myanmar Department of Public Health, National Strategic Plan for Intensifying Malaria Control and Accelerating Progress towards Malaria Elimination.

6. Bennett, A., Avanceña, A.L.V., Wegbreit, J., Cotter, C., Roberts, K. and Gosling, R. (2017). Engaging the private sector in malaria surveillance: a review of strategies and recommendations for elimination settings. Malaria Journal, 16:252.

https://malariajournal.biomedcentral.com/articles/10.1186/s12936-017-1901-1 
7. Nonaka D, Vongseththa K, Kobayashi J, Bounyadeth S, Kano S, Phompida S, et al. Public and private sector treatment of malaria in Lao PDR. Acta Trop. 2009;112:283-7.

8. Zelman, A. Costs and cost-effectiveness of malaria reactive case detection using loop-mediated isothermal amplication compared to microscopy in the low transmission setting of Aceh Province, Indonesia. Malar J (2018) 17:220.

9. Marston et al. Cost analysis of the development and implementation of a spatial decision support system for malaria elimination in Solomon Islands. Malaria Journal 2014, 13:325.

10. Gold M, Siegel J, Russell L, and Weinstein M. Cost-effectiveness in Health and Medicine, 1996, New York, Oxford University Press. Cited in CISM Protocol for the Costing of MALTEM in Southern Mozambique.

11. World Health Organization, A Framework for Malaria Elimination, 2017.

\section{Tables}




\begin{tabular}{|c|c|c|}
\hline & Intervention Category & Activities \\
\hline \multirow{9}{*}{$\begin{array}{l}\text { Start-up } \\
\text { Costs }\end{array}$} & \multirow{5}{*}{$\begin{array}{l}\text { Introduction of electronic surveillance } \\
\text { system (DHIS 2) }\end{array}$} & System design \\
\hline & & System configuration \\
\hline & & Piloting \\
\hline & & Training \\
\hline & & Design of surveillance bulletins \\
\hline & \multirow[t]{4}{*}{ Introduction of mobile reporting } & Mobile application design \\
\hline & & Mobile application development \\
\hline & & Piloting mobile applications \\
\hline & & Training providers on mobile reporting \\
\hline \multirow[t]{2}{*}{$\begin{array}{l}\text { Capital } \\
\text { Costs }\end{array}$} & $\begin{array}{l}\text { Introduction of electronic surveillance } \\
\text { system (DHIS 2) }\end{array}$ & Procurement of hardware: desktops \\
\hline & Introduction of mobile reporting & $\begin{array}{l}\text { Procurement of hardware: mobile } \\
\text { devices }\end{array}$ \\
\hline \multirow{8}{*}{$\begin{array}{l}\text { Recurrent } \\
\text { Costs }\end{array}$} & \multirow[t]{6}{*}{ Electronic surveillance system (DHIS 2) } & Data entry (centralized) \\
\hline & & System upgrades \& maintenance \\
\hline & & Server hosting \\
\hline & & $\begin{array}{l}\text { Supportive supervision of malaria } \\
\text { providers }\end{array}$ \\
\hline & & $\begin{array}{l}\text { Data quality assurance, monitoring \& } \\
\text { evaluation }\end{array}$ \\
\hline & & $\begin{array}{l}\text { Production \& dissemination of } \\
\text { surveillance reports }\end{array}$ \\
\hline & \multirow[t]{2}{*}{ Mobile reporting } & Mobile app upgrades \& maintenance \\
\hline & & Mobile data packages \\
\hline
\end{tabular}

Table 2. Financial and Economic Costs of Cambodia Electronic Surveillance Intervention and Provider Mobile Reporting Intervention 
Cost Category

Electronic

Surveillance
Mobile

Reporting
Total

$\%$

Cost

Financial Costs

Start-up

System Design and Configuration

(DHIS2)

Piloting (DHIS2)

$\$ 10,786$

$\mathrm{N} / \mathrm{A}$

$\$ 10,786$

$2.5 \%$

Training (DHIS2)

$\$ 7,792$

$\mathrm{N} / \mathrm{A}$

$\$ 7,792$

$1.8 \%$

MCS App Design and Development

N/A

$\$ 24,817$

$\$ 24,817$

$5.7 \%$

MCS App Piloting

N/A

$\$ 9,475$

$\$ 9,475$

$2.2 \%$

MCS App Training

N/A

$\$ 8,054$

$\$ 8,054$

$1.9 \%$

Surveillance Bulletin Design

$\$ 2,366$

$\mathrm{N} / \mathrm{A}$

$\$ 2,366$

$0.5 \%$

Server Set-up

$\$ 150$

$\$ 73,125$

N/A

$\$ 150$

$0.0 \%$

Sub-total Start-up

$\$ 42,346$

$\$ 115,471$

$26.5 \%$

\section{Capital}

Equipment (desktops)

$\$ 4,800$

N/A

Equipment (mobile devices)

$\$ 4,800$

Sub-total Capital

Recurrent

DHIS2 Maintenance \& Routine Upgrades

$\$ 22,592$

$\mathrm{N} / \mathrm{A}$

$\$ 22,592$

$5.2 \%$

DHIS2 Software upgrades

Server hosting

$\$ 7,620$

MCS App Maintenance \& Routine

Upgrades

N/A

N/A

$\$ 7,620$

$0.0 \%$

$\$ 32,182$

$\$ 32,182$

$7.4 \%$

Procure electronic report: Monthly mobile data packages

N/A

Provider Social and Behavioral Change Communication (SBCC) \& Supervision

$\$ 17,784$

$\$$

104,580

$\$ 104,580$

$24.0 \%$

$\$ 17,784$

$8.2 \%$

$\$ 35,569$

$\$ 47,996$

$\$ 154,546$

$\$ 202,542 \quad 47 \%$

$\$ 125,921$

$\$ 309,047$

Total costs 


\begin{tabular}{|c|c|c|c|c|}
\hline Annual Costs & $\$ 41,974$ & $\$ 221,749$ & $\$ 144,989$ & N/A \\
\hline \multirow[t]{2}{*}{$\begin{array}{l}\text { Annual Cost per mobile reporting provider } \\
\text { ( } n=585 \text { providers) }\end{array}$} & N/A & $\$ 176$ & & N/A \\
\hline & & & $\$ 248$ & \\
\hline $\begin{array}{l}\text { Annual cost per provider ( } \mathrm{n}=710 \\
\text { providers) }\end{array}$ & $\$ 59$ & $\mathrm{~N} / \mathrm{A}$ & $\$ 204$ & $\mathrm{~N} / \mathrm{A}$ \\
\hline \multicolumn{5}{|l|}{ Economic Costs } \\
\hline \multicolumn{5}{|l|}{ Start-up } \\
\hline System Design (DHIS2) & $\$ 214,243$ & $\mathrm{~N} / \mathrm{A}$ & $\$ 214,243$ & $32.2 \%$ \\
\hline Piloting (DHIS2) & $\$ 11,438$ & $\mathrm{~N} / \mathrm{A}$ & $\$ 11,438$ & $1.7 \%$ \\
\hline Training (DHIS2) & $\$ 8,263$ & $\mathrm{~N} / \mathrm{A}$ & $\$ 8,263$ & $1.2 \%$ \\
\hline MCS App Design and Development & N/A & $\$ 26,317$ & $\$ 26,317$ & $3.9 \%$ \\
\hline MCS App Piloting & N/A & $\$ 10,048$ & $\$ 10,048$ & $1.5 \%$ \\
\hline MCS App Training & N/A & $\$ 10,800$ & $\$ 10,800$ & $1.6 \%$ \\
\hline Surveillance Bulletin Design & 2,509 & $\mathrm{~N} / \mathrm{A}$ & $\$ 2,508$ & $0.4 \%$ \\
\hline Server Set-up & 159 & $\mathrm{~N} / \mathrm{A}$ & $\$ 159$ & $0.0 \%$ \\
\hline Sub-total Start-up & 236,611 & $\$ 47,165$ & $\$ 283,777$ & $42.7 \%$ \\
\hline \multicolumn{5}{|l|}{ Capital } \\
\hline Equipment (desktops) & $\$ 5,090$ & $\mathrm{~N} / \mathrm{A}$ & $\$ 5,090$ & $0.8 \%$ \\
\hline Equipment (mobile devices) & N/A & $\$ 118,934$ & $\$ 118,934$ & $17.9 \%$ \\
\hline Sub-total Capital & $\$ 5,090$ & $\$ 118,934$ & $\$ 124,024$ & $18.6 \%$ \\
\hline \multicolumn{5}{|l|}{ Recurrent } \\
\hline DHIS2 Maintenance \& Routine Upgrades & $\$ 22,592$ & $\mathrm{~N} / \mathrm{A}$ & $\$ 22,592$ & $3.4 \%$ \\
\hline DHIS2 Software upgrades & $\$ 30,000$ & $\mathrm{~N} / \mathrm{A}$ & $\$ 30,000$ & $4.5 \%$ \\
\hline Server hosting & $\$ 7,620$ & $\mathrm{~N} / \mathrm{A}$ & $\$ 7,620$ & $1.1 \%$ \\
\hline $\begin{array}{l}\text { MCS App Maintenance \& Routine } \\
\text { Upgrades }\end{array}$ & & $\$ 35,569$ & $\$ 32,182$ & $4.8 \%$ \\
\hline \multirow[t]{2}{*}{$\begin{array}{l}\text { Procure electronic report: Monthly mobile } \\
\text { data packages }\end{array}$} & & $\$ 129,483$ & $\$ 129,483$ & \\
\hline & & & & $19.5 \%$ \\
\hline $\begin{array}{l}\text { Provider Social and Behavioral Change } \\
\text { Communication (SBCC) \& Supervision }\end{array}$ & $\$ 17,784$ & $\$ 17,784$ & $\$ 35,569$ & \\
\hline
\end{tabular}




\begin{tabular}{|c|c|c|c|c|}
\hline Sub-total Recurrent & $\$ 77,996$ & $\$ 182,836$ & $\$ 257,445$ & $38.7 \%$ \\
\hline Total costs & $\$ 321,395$ & $\$ 348,935$ & $\$ 665,246$ & $100 \%$ \\
\hline Annual Costs & $\$ 106,331$ & $\$ 116,312$ & $\$ 221,749$ & N/A \\
\hline \multirow[t]{2}{*}{$\begin{array}{l}\text { Annual Cost per mobile reporting provider } \\
\text { ( } n=585 \text { providers) }\end{array}$} & $\mathrm{N} / \mathrm{A}$ & $\$ 199$ & $\$ 379$ & \\
\hline & & & & $\mathrm{N} / \mathrm{A}$ \\
\hline $\begin{array}{l}\text { Annual cost per provider ( } n=710 \\
\text { providers) }\end{array}$ & $\$ 59$ & $\mathrm{~N} / \mathrm{A}$ & $\$ 312$ & N/A \\
\hline
\end{tabular}

Table 3. Financial and Economic Costs of Lao PDR Electronic Surveillance Intervention and Provider Mobile Reporting Intervention 


\begin{tabular}{|c|c|c|c|c|}
\hline Cost Category & $\begin{array}{l}\text { Electronic } \\
\text { Surveillance }\end{array}$ & $\begin{array}{l}\text { Mobile } \\
\text { Reporting }\end{array}$ & $\begin{array}{l}\text { Total } \\
\text { Costs }\end{array}$ & $\%$ \\
\hline \multicolumn{5}{|l|}{ Financial Costs } \\
\hline \multicolumn{5}{|l|}{ Start-up } \\
\hline System Design and Configuration (DHIS2) & $\$ 8,845$ & $\mathrm{~N} / \mathrm{A}$ & $\$ 8,845$ & $5.8 \%$ \\
\hline Piloting (DHIS2) & $\$ 595$ & $\mathrm{~N} / \mathrm{A}$ & $\$ 595$ & $0.4 \%$ \\
\hline Training (DHIS2) & $\$ 7,473$ & $\mathrm{~N} / \mathrm{A}$ & $\$ 7,473$ & $4.9 \%$ \\
\hline Server Set-up & $\$ 150$ & $\mathrm{~N} / \mathrm{A}$ & $\$ 150$ & $0.1 \%$ \\
\hline Surveillance Bulletin Design & $\$ 5,107$ & $\mathrm{~N} / \mathrm{A}$ & $\$ 5,107$ & $3.3 \%$ \\
\hline MCS App Design and Development & N/A & $\$ 27,362$ & $\$ 27,362$ & $17.8 \%$ \\
\hline MCS App Piloting & N/A & $\$ 5,659$ & $\$ 5,659$ & $3.7 \%$ \\
\hline MCS App Training for Providers & N/A & $\$ 8,281$ & $\$ 8,281$ & $5.4 \%$ \\
\hline Total & $\$ 22,170$ & $\$ 41,080$ & $\$ 63,250$ & $41.4 \%$ \\
\hline \multicolumn{5}{|l|}{ Capital } \\
\hline Hardware (desktops) & $\$ 2,400$ & $\mathrm{~N} / \mathrm{A}$ & $\$ 2,400$ & $1.6 \%$ \\
\hline Equipment (tablets for field officers) & $\$ 4,800$ & $\mathrm{~N} / \mathrm{A}$ & $\$ 4,800$ & $3.1 \%$ \\
\hline Sub-total Capital (annual) & $\$ 7,200$ & N/A & $\$ 7,200$ & $4.7 \%$ \\
\hline \multicolumn{5}{|l|}{ Recurrent } \\
\hline DHIS2 Maintenance \& Routine Upgrades & $\$ 8,245$ & $\mathrm{~N} / \mathrm{A}$ & $\$ 8,245$ & $5.4 \%$ \\
\hline Server hosting & $\$ 5,976$ & $\mathrm{~N} / \mathrm{A}$ & $\$ 5,976$ & $3.9 \%$ \\
\hline $\begin{array}{l}\text { MCS App Maintenance \& Routine } \\
\text { Upgrades }\end{array}$ & N/A & $\$ 12,877$ & $\$ 12,877$ & $8.4 \%$ \\
\hline Monthly mobile data packages & N/A & $\$ 8,640$ & $\$ 8,640$ & $5.7 \%$ \\
\hline Provider BCC \& Supervision & $\$ 22,245$ & $\$ 22,245$ & $\$ 44,490$ & $29.4 \%$ \\
\hline Monitoring and Evaluation & $\$ 1,750$ & $\mathrm{~N} / \mathrm{A}$ & $\$ 1,750$ & $1.1 \%$ \\
\hline Sub-total Recurrent & $\$ 38,216$ & $\$ 43,762$ & $\$ 82,428$ & $53.9 \%$ \\
\hline Total costs & $\$ 67,586$ & $\$ 84,842$ & $\$ 152,878$ & $100 \%$ \\
\hline Annual Costs & $\$ 22,528$ & $\$ 43,111$ & $\$ 50,959$ & $\mathrm{~N} / \mathrm{A}$ \\
\hline $\begin{array}{l}\text { Annual cost per private provider reporting } \\
\text { by mobile }(n=250)\end{array}$ & $\$ 35$ & $\$ 87$ & $\$ 204$ & $\mathrm{~N} / \mathrm{A}$ \\
\hline
\end{tabular}




\section{Economic Costs}

\section{Start-up}

\begin{tabular}{lllll} 
System Design and Configuration (DHIS2) & $\$ 168,446$ & N/A & $\$ 168,446$ & $43,1 \%$ \\
\hline Piloting (DHIS2) & $\$ 631.18$ & N/A & $\$ 631.18$ & $0.2 \%$ \\
\hline Training (DHIS2) & $\$ 7925$ & N/A & $\$ 7,924.50$ & $2.0 \%$ \\
\hline Server Set-up & $\$ 159$ & N/A & $\$ 159$ & $0.0 \%$ \\
\hline Surveillance Bulletin Design & $\$ 5,415$ & N/A & $\$ 5,415$ & $1.4 \%$ \\
\hline MCS App Design and Development & N/A & $\$ 28,781$ & $\$ 28,781$ & $7.4 \%$ \\
\hline MCS App Piloting & N/A & $\$ 6,001$ & $\$ 6,001$ & $1.5 \%$ \\
\hline MCS App Training for Providers & N/A & $\$ 10,156$ & $\$ 10,156$ & $2.6 \%$ \\
\hline Sub-Total Startup & $\mathbf{\$ 1 8 2 , 5 7 6}$ & $\mathbf{\$ 4 4 , 9 3 8}$ & $\mathbf{\$}$ & $58.2 \%$ \\
\hline
\end{tabular}

\section{Capital}

\begin{tabular}{|c|c|c|c|c|}
\hline Hardware (desktops) & $\$ 2,545$ & N/A & $\$ 2,545$ & $0.7 \%$ \\
\hline Equipment (tablets for field officers) & $\$ 5,090$ & $\mathrm{~N} / \mathrm{A}$ & $\$ 5,090$ & $1.3 \%$ \\
\hline Equipment (provider smartphones) & N/A & 39,767 & $\$ 39,767$ & $10.2 \%$ \\
\hline Sub-total Capital (annual) & $\$ 7,635$ & $\$ 39,767$ & $\$ 47,402$ & $12.1 \%$ \\
\hline \multicolumn{5}{|l|}{ Recurrent } \\
\hline DHIS2 Maintenance \& Routine Upgrades & $\$ 8,245$ & $\mathrm{~N} / \mathrm{A}$ & $\$ 8,245$ & $2.1 \%$ \\
\hline DHIS2 Software Upgrades & $\$ 30,000$ & $\mathrm{~N} / \mathrm{A}$ & $\$ 30,000$ & $7.7 \%$ \\
\hline Server hosting & $\$ 5,976$ & N/A & $\$ 5,976$ & $1.5 \%$ \\
\hline $\begin{array}{l}\text { MCS App Maintenance \& Routine } \\
\text { Upgrades }\end{array}$ & N/A & $\$ 12,877$ & $\$ 12,877$ & $3.3 \%$ \\
\hline Monthly mobile data packages & $\mathrm{N} / \mathrm{A}$ & $\$ 12,177$ & $\$ 12,177$ & $3.1 \%$ \\
\hline Provider BCC \& Supervision & $\$ 22,470$ & $\$ 22,470$ & $\$ 44,940$ & $11.5 \%$ \\
\hline Monitoring and Evaluation & $\$ 1,750$ & $\mathrm{~N} / \mathrm{A}$ & $\$ 1,750$ & $0.4 \%$ \\
\hline Sub-total Recurrent & $\$ 68,441$ & $\$ 47,524$ & $\stackrel{\$}{115.965}$ & $29.7 \%$ \\
\hline Total Costs & $\$ 258,652$ & $\$ 132,229$ & $\$ 390,880$ & $100 \%$ \\
\hline Annual Costs & $\$ 86,217$ & $\$ 44,076$ & $\$ 130,293$ & $\mathrm{~N} / \mathrm{A}$ \\
\hline Annual cost per private provider reporting & $\$ 345$ & & $\$ 521$ & $\mathrm{~N} / \mathrm{A}$ \\
\hline
\end{tabular}


Table 4. Financial and Economic Costs of Myanmar Electronic Surveillance Intervention and Mobile Reporting Intervention among Field-based Supervisors 


\begin{tabular}{lllll}
\hline Cost Category & Electronic & Tablet & Total Cost & Surveillance \\
& Reporting & & \\
\hline
\end{tabular}

\section{Financial Costs}

\section{Start-up}

\begin{tabular}{|c|c|c|c|c|}
\hline System Design and Configuration (DHIS2) & $\$ 39,363$ & N/A & $\$ 39,363$ & $3.0 \%$ \\
\hline Piloting (DHIS2) & $\$ 4,832$ & $\mathrm{~N} / \mathrm{A}$ & $\$ 4,832$ & $0.4 \%$ \\
\hline Training (DHIS2) & $\$ 9,361$ & $\mathrm{~N} / \mathrm{A}$ & $\$ 9,361$ & $0.7 \%$ \\
\hline Server setup & $\$ 300$ & $\mathrm{~N} / \mathrm{A}$ & $\$ 300$ & $0.0 \%$ \\
\hline Surveillance Bulletin design & $\$ 2,443$ & $\mathrm{~N} / \mathrm{A}$ & $\$ 2,443$ & $0.2 \%$ \\
\hline App piloting & N/A & $\$ 4,178$ & $\$ 4,178$ & $0.3 \%$ \\
\hline App training for field officers & N/A & $\$ 12,672$ & $\$ 12,672$ & $1.0 \%$ \\
\hline Sub-total Start-up & $\$ 56,299$ & $\$ 16,850$ & $\$ 73,149$ & $5.6 \%$ \\
\hline \multicolumn{5}{|l|}{ Capital } \\
\hline Tablets (for mobile reporting) & N/A & $\$ 80,200$ & $\$ 80,200$ & $6.1 \%$ \\
\hline Hardware (desktops) & $\$ 9,600$ & $\mathrm{~N} / \mathrm{A}$ & $\$ 9,600$ & $0.7 \%$ \\
\hline Sub-total capital (annual) & $\$ 9,600$ & $\$ 80,200$ & $\$ 89,800$ & $6.8 \%$ \\
\hline \multicolumn{5}{|l|}{ Recurrent } \\
\hline DHIS2 Maintenance \& Routine Upgrades & $\$ 10,070$ & $\mathrm{~N} / \mathrm{A}$ & $\$ 10,070$ & $0.8 \%$ \\
\hline Server hosting & $\$ 13,680$ & $\mathrm{~N} / \mathrm{A}$ & $\$ 13,680$ & $1.0 \%$ \\
\hline $\begin{array}{l}\text { Provider Social and Behavior Change } \\
\text { Communication and Supervision }\end{array}$ & $\$ 546,840$ & $\$ 546,840$ & $\$ 1,093,680$ & $83.1 \%$ \\
\hline Mobile data packages & N/A & $\$ 36,000$ & $\$ 36,000$ & $2.7 \%$ \\
\hline Sub-total Recurrent & $\$ 570,590$ & $\$ 582,840$ & $\$ 1,153,430$ & $87.6 \%$ \\
\hline Total costs & $\$ 636,489$ & $\$ 679,890$ & $\$ 1,316,379$ & $100 \%$ \\
\hline Annual Costs & $\$ 211,324$ & $\$ 226,630$ & $\$ 437,954$ & \\
\hline Cost per provider ( 16,000 providers) & $\$ 13$ & $\$ 14$ & $\$ 27$ & \\
\hline
\end{tabular}

\section{Economic Costs}

\section{Start-up}

System Design and Configuration (DHIS2) $\quad \$ 200,809 \quad$ N/A $\quad \$ 200,809 \quad 12.8 \%$ 


\begin{tabular}{|c|c|c|c|c|}
\hline Piloting (DHIS2) & $\$ 5,124$ & $\mathrm{~N} / \mathrm{A}$ & $\$ 5,124$ & $0.3 \%$ \\
\hline Training (DHIS2) & $\$ 11,592$ & $\mathrm{~N} / \mathrm{A}$ & $\$ 11,592$ & $0.7 \%$ \\
\hline Server setup & $\$ 318$ & $\mathrm{~N} / \mathrm{A}$ & $\$ 318$ & $0.0 \%$ \\
\hline Surveillance Bulletin design & $\$ 2,590$ & $\mathrm{~N} / \mathrm{A}$ & $\$ 2,590$ & $0.2 \%$ \\
\hline App piloting & $\mathrm{N} / \mathrm{A}$ & $\$ 4,430$ & $\$ 4,430$ & $0.3 \%$ \\
\hline App training for field officers & $\mathrm{N} / \mathrm{A}$ & $\$ 13,438$ & $\$ 13,438$ & $0.9 \%$ \\
\hline App development & N/A & $\$ 27,549,31$ & $\$ 27,549$ & $1.8 \%$ \\
\hline Sub-total Start-up & $\$ 220,434$ & $\$ 45,418$ & $\$ 265,851$ & $16.9 \%$ \\
\hline \multicolumn{5}{|l|}{ Capital } \\
\hline Tablets (for mobile reporting) & N/A & $\$ 85,048$ & $\$ 85,048$ & $5.4 \%$ \\
\hline Hardware (desktops) & $\$ 10,180$ & $\mathrm{~N} / \mathrm{A}$ & $\$ 10,180$ & $0.6 \%$ \\
\hline Sub-total capital (annual) & $\$ 10,180$ & $\$ 85,048$ & $\$ 95,228$ & $6.1 \%$ \\
\hline \multicolumn{5}{|l|}{ Recurrent } \\
\hline DHIS2 Maintenance \& Routine Upgrades & $\$ 40,070$ & $\mathrm{~N} / \mathrm{A}$ & $\$ 40,070$ & $2.6 \%$ \\
\hline Server hosting & $\$ 13,680$ & $\mathrm{~N} / \mathrm{A}$ & $\$ 13,680$ & $0.9 \%$ \\
\hline $\begin{array}{l}\text { Provider Social and Behavior Change } \\
\text { Communication and Supervision }\end{array}$ & $\$ 546,840$ & $\$ 546,840$ & $\$ 1,093,680$ & $69.7 \%$ \\
\hline Mobile data packages & N/A & $\$ 38,244$ & $\$ 38,244$ & $2.4 \%$ \\
\hline App maintenance & N/A & $\$ 22,500$ & $\$ 22,500$ & $1.4 \%$ \\
\hline Sub-total Recurrent & $\$ 600,590$ & $\$ 607,584$ & $\$ 1,208,174$ & $77.0 \%$ \\
\hline Total costs & $\$ 831,204$ & $\$ 738,049$ & $\$ 1,569,253$ & $100 \%$ \\
\hline Annual Costs & $\$ 277,068$ & $\$ 236,085$ & $\$ 504,456$ & $\mathrm{~N} / \mathrm{A}$ \\
\hline Cost per provider ( 16,000 providers) & $\$ 17$ & $\$ 15$ & $\$ 32$ & $\mathrm{~N} / \mathrm{A}$ \\
\hline
\end{tabular}

Table 5. Comparisons of Estimated Annual Costs of Electronic Surveillance with National Malaria Program 


\begin{tabular}{|c|c|c|c|c|c|}
\hline & $\begin{array}{l}\text { Economic } \\
\text { Cost of } \\
\text { Electronic } \\
\text { Surveillance }\end{array}$ & $\begin{array}{l}\text { Estimated } \\
\text { Annual Costs } \\
\text { National Malaria } \\
\text { Strategic Plan }\end{array}$ & $\begin{array}{l}\text { Estimated } \\
\text { Cost of } \\
\text { Surveillance } \\
\text { in NMSP }\end{array}$ & $\begin{array}{l}\text { \% Electronic } \\
\text { Surveillance to } \\
\text { Annual } \\
\text { Program Cost }\end{array}$ & $\begin{array}{l}\text { \% Electronic } \\
\text { Surveillance to } \\
\text { Estimated } \\
\text { surveillance } \\
\text { Budget }\end{array}$ \\
\hline Cambodia & $\begin{array}{l}\$ 221,749 \\
(14 \text { out of } \\
25 \\
\text { provinces })\end{array}$ & $\$ 50,354,592$ & $\mathrm{~N} / \mathrm{A}$ & $0.4 \%$ & N/A \\
\hline Lao PDR & $\begin{array}{l}\$ 130,293 \text { (5 } \\
\text { out of } 17 \\
\text { provinces) }\end{array}$ & $\$ 14,557,696$ & $\$ 2,260,000$ & $0.9 \%$ & $5.8 \%$ \\
\hline Myanmar & $\begin{array}{l}\$ 504,456 \\
\text { (entire } \\
\text { country) }\end{array}$ & $\$ 92,600,000$ & $\$ 6,400,000$ & $0.5 \%$ & $7.9 \%$ \\
\hline
\end{tabular}

\section{Figures}




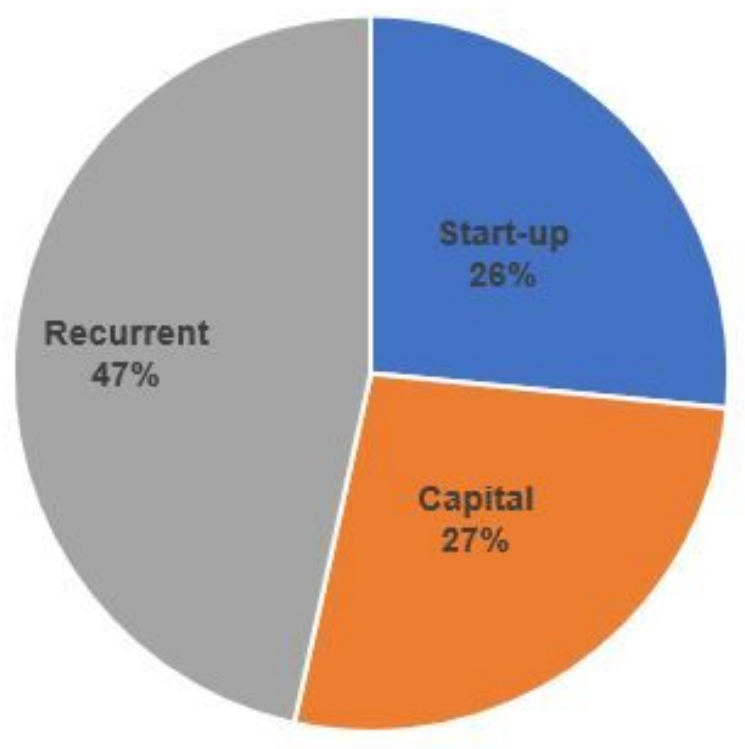

Figure 1a.

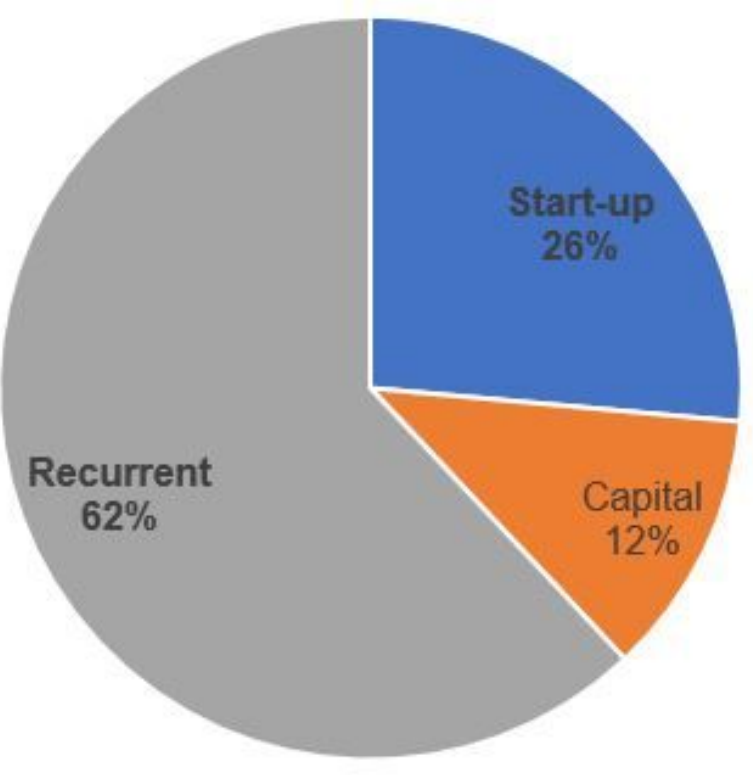

Figure $1 \mathrm{~b}$.

\section{Figure 1}

a and $1 \mathrm{~b}$ shows pie charts for the financial and economic costs for electronic surveillance and mobile reporting in Cambodia. Figure 1a. Cambodia Electronic Surveillance and Mobile Reporting Financial Costs by Category Figure 1b. Cambodia Electronic Surveillance and Mobile Reporting Economic Costs by Category 


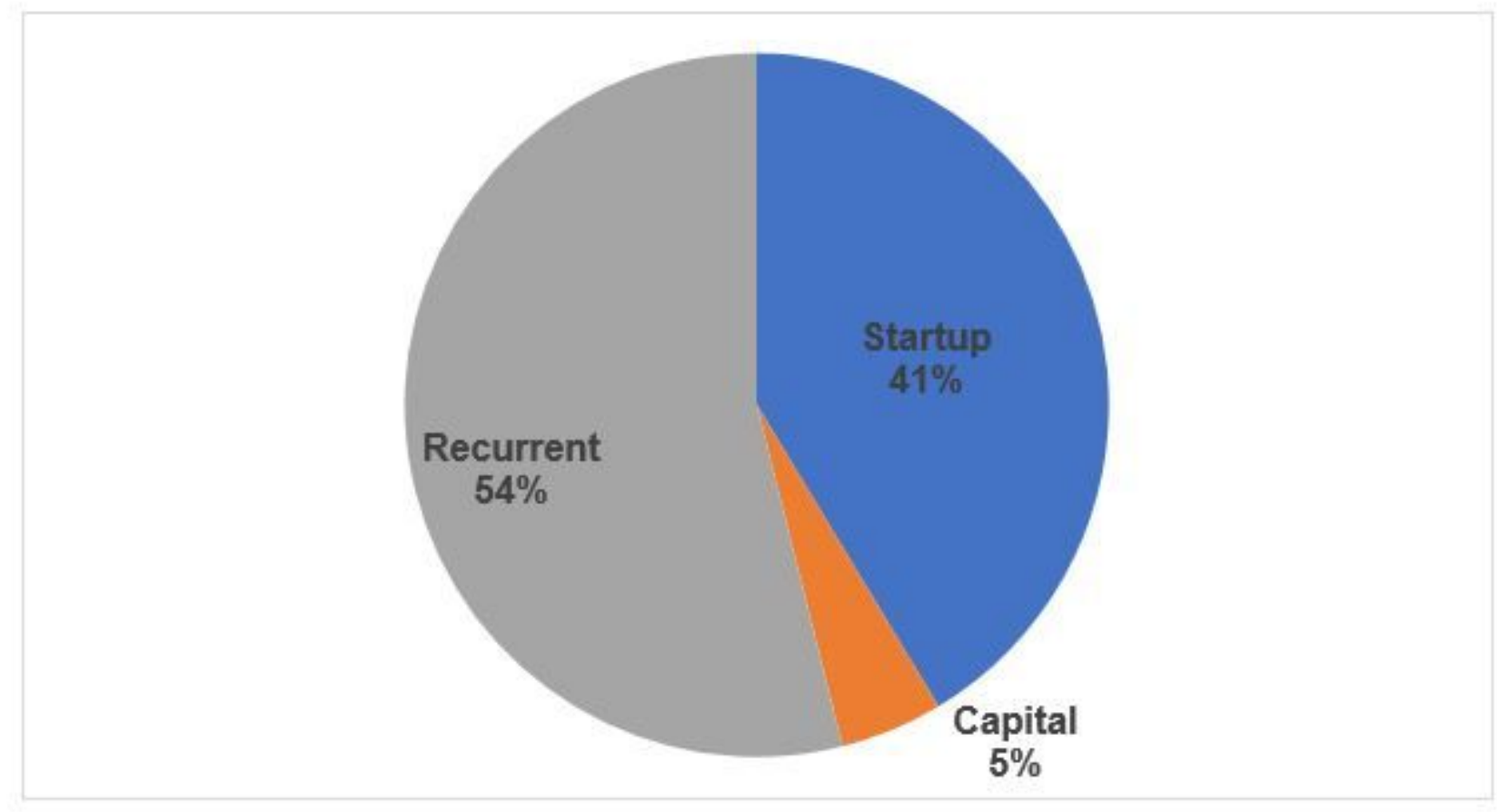

Figure 2a.

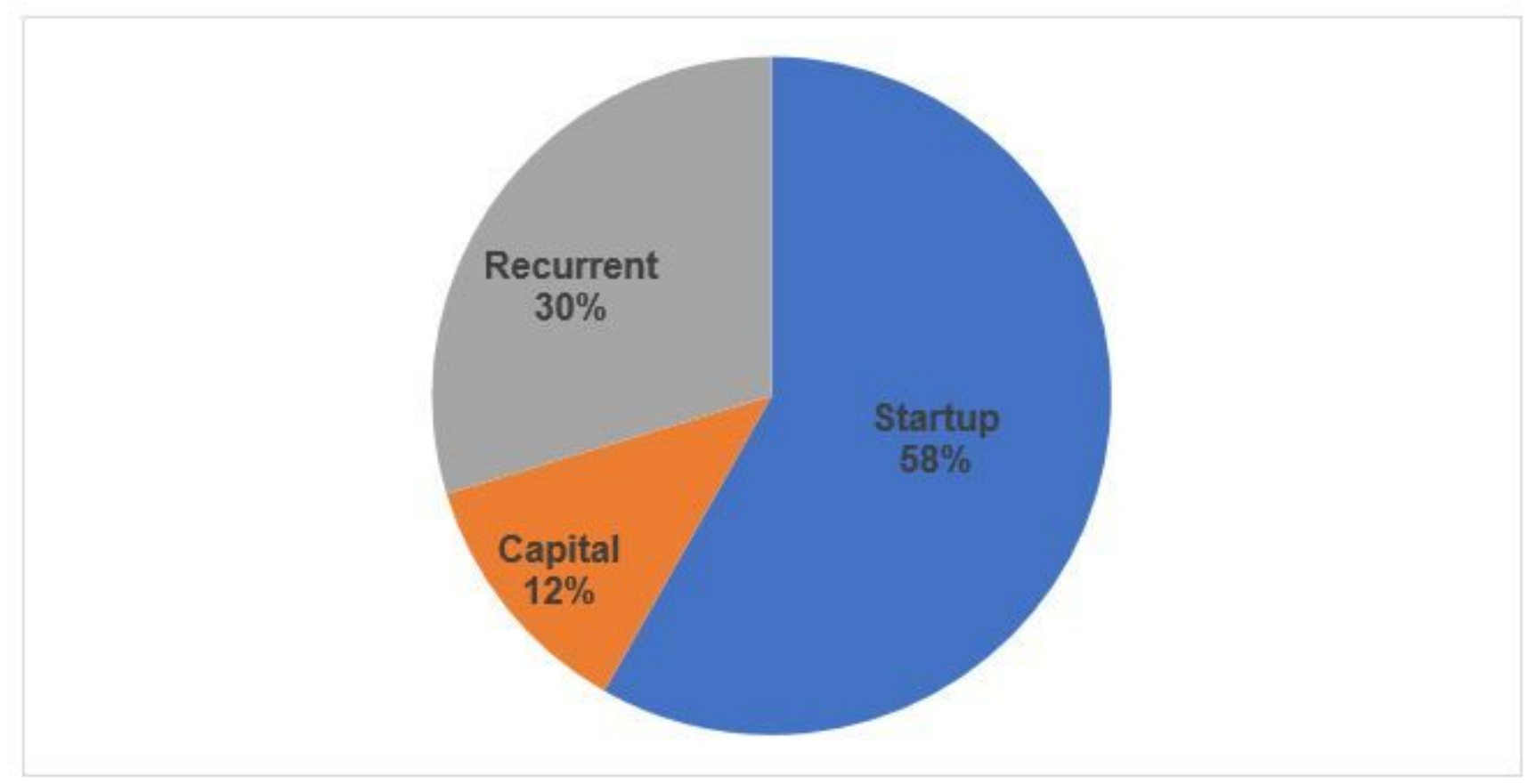

Figure 2b.

\section{Figure 2}

Figure 2a. Financial Cost of Laos Electronic Surveillance and Mobile Reporting by Category Figure 2b. Economic Cost of Laos Electronic Surveillance and Mobile Reporting by Category 


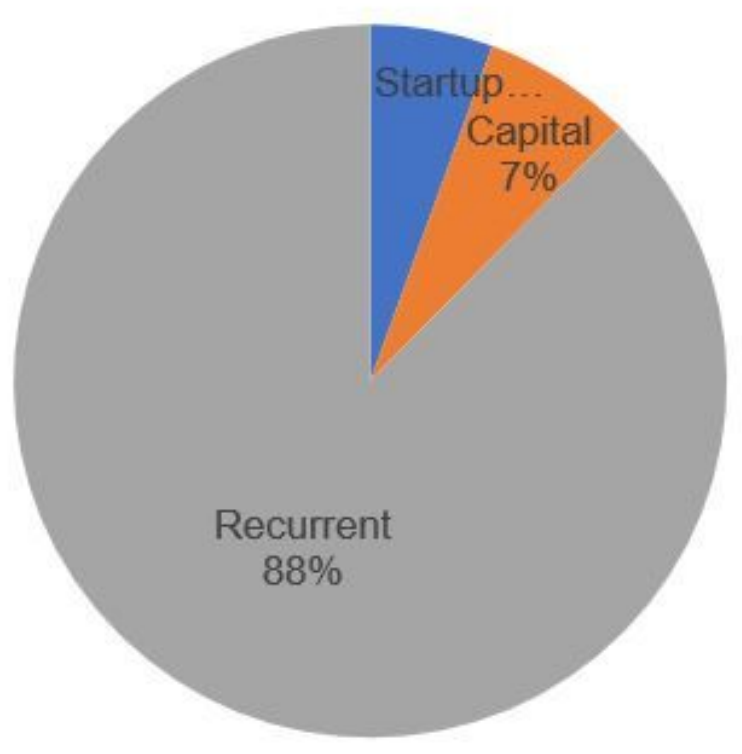

Figure 3a.

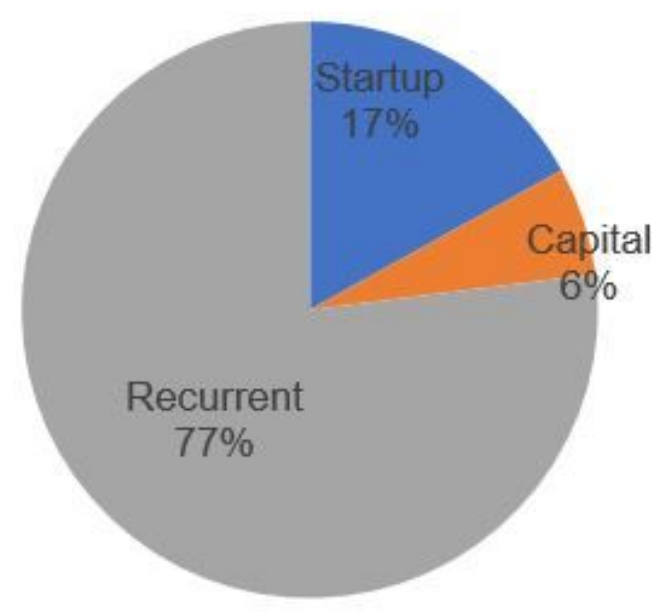

Figure $3 b$.

\section{Figure 3}

a and 3b. Cost of Myanmar Electronic Surveillance with Generic DHIS2 app Figure 3a. Financial Costs of Malaria Electronic Surveillance in Myanmar Figure 3b. Economic Costs of Malaria Electronic Surveillance in Myanmar 